\title{
MITF Positive
}

National Cancer Institute

\section{Source}

National Cancer Institute. MITF Positive. NCI Thesaurus. Code C146659.

An indication that MITF expression has been detected in a sample. 